Check for updates

Cite this: RSC Adv., 2021, 11, 38667

Received 19th September 2021

Accepted 18th November 2021

DOI: $10.1039 / \mathrm{d} 1 \mathrm{ra07014b}$

rsc.li/rsc-advances

\section{Graphene oxide-catalyzed trifluoromethylation of alkynes with quinoxalinones and Langlois' reagent $\uparrow$}

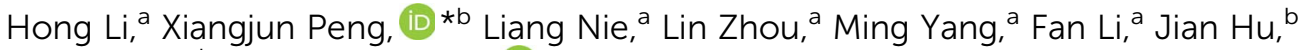 \\ Zhiyang $\mathrm{Yao}^{\mathrm{b}}$ and Liangxian Liu (D) *a
}

The direct $\mathrm{C}-\mathrm{H}$ trifluoromethylation of alkynes and quinoxalinones has been achieved using a graphene oxide/Langlois' reagent system. This multi-component tandem reaction using graphene oxide as the catalyst and Langlois' reagent as the robust $\mathrm{CF}_{3}$ radical source results in the formation of olefinic $\mathrm{C}-\mathrm{CF}_{3}$ to access a series of 3 -trifluoroalkylated quinoxalin-2(1H)-ones.

\section{Introduction}

Graphene oxide (GO), exfoliated from oxidized graphite, has a large $\pi$-network and specific surface area, abundant defects and a wide range of oxygen functional groups involving alcohols, epoxides, carboxylic acids and bridging 1,3 -ethers. ${ }^{1}$ This ultrathin 2D carbocatalyst, using its inherent reactivity of oxidation, acidity and catalytic activity, has been successfully applied to oxidation, acid- or base-catalyzed transformations, oxidative coupling of amines, hydration of alkynes, aza-Michael addition reactions of amines and $\alpha, \beta$-unsaturated compounds, ring opening of epoxy compounds, and dehydrogenationoxidation of nitrogen heterocycles. ${ }^{2}$ However, GO as a catalyst in organic transformation still faces serious challenges, compared with its applications in electronics, optical materials, solar cells and biosensors. ${ }^{3}$

Quinoxalin-2 $(1 H)$-ones are important compounds that exist in various bioactive natural products and pharmaceutical compounds, especially $\mathrm{CF}_{3}$-containing quinoxalin- $2(1 H)$-ones showing potent anticancer activities (Fig. 1 ). ${ }^{4}$

A tremendous amount of trifluoromethylation strategies have been developed and are widespread in the pharmaceutical, agrochemical and material science fields ever since the incorporation of the $\mathrm{CF}_{3}$ group was introduced into different organic molecules. ${ }^{5}$ Various trifluoroalkylated regents, such as Langlois (sodium trifluoromethanesulfinate, $\mathrm{NaSO}_{2} \mathrm{CF}_{3}$ ), ${ }^{6}$ Togni, ${ }^{7}$ Umemoto, ${ }^{8}$ and Ruppert-Prakash, ${ }^{9}$ have been developed and successfully employed in trifluoromethylation reactions. In this

\footnotetext{
${ }^{a}$ Key Laboratory of Organo-Pharmaceutical Chemistry of Jiangxi Province, Gannan Normal University, Ganzhou, Jiangxi 341000, P. R. China

${ }^{b}$ Key Laboratory of Prevention and Treatment of Cardiovascular and Cerebrovascular Diseases of Ministry of Education, Gannan Medical University, Ganzhou 341000, P. R. China. E-mail: liuliangxian1962@163.com

$\dagger$ Electronic supplementary information (ESI) available: Experimental procedures, control experiments and characterization of $\mathrm{GO},{ }^{1} \mathrm{H}$ and ${ }^{13} \mathrm{C}$ NMR spectra of compounds 3. CCDC 2088404. For ESI and crystallographic data in CIF or other electronic format see DOI: 10.1039/d1ra07014b
}

regard, many research groups have explored diverse synthetic approaches involving inorganic/organic oxidants, photocatalysis, or electrocatalysis, which synthesize 3-trifluoromethylquinoxalin-2(1H)-ones using quinoxalin-2(1H)ones and $\mathrm{CF}_{3} \mathrm{SO}_{2} \mathrm{Na}$, $\mathrm{TMSCF}_{3}$, or $\mathrm{Zn}\left(\mathrm{SO}_{2} \mathrm{CF}_{3}\right)_{2}$ as the trifluoromethylated agent (Scheme 1, eqn (1)). ${ }^{10}$ Within this arena, Langlois' reagent, as an electrophilic trifluoromethyl radical, has been frequently used in the addition of electron-rich olefins and alkynes (Scheme 1, eqn (2)). ${ }^{11}$ In particular, a few threecomponent protocols of " $\mathrm{CF}_{3}$ "-radical addition to terminal or unactivated alkenes with Langlois' reagent have delivered various 3-trifluoroalkylated quinoxalin-2(1H)-ones under metal-free conditions (Scheme 1 , eqn (3)). ${ }^{12}$ These trifluoroalkylated reactions exhibit mild reaction conditions, low catalyst loading, ubiquity and versatile functionality of directing $\mathrm{C}^{-} \mathrm{CF}_{3}$ activation. Inspired by these successful discoveries, we turned our attention to the multi-component trifluoromethylation of alkynes with quinoxalinones and Langlois' reagent. We envision that $\mathrm{GO}$ will facilitate $\mathrm{CF}_{3} \mathrm{SO}_{2}$ $\mathrm{Na}$ to generate the electrophilic $\mathrm{CF}_{3}$ radical intermediate, which enables an intermolecular addition with alkynes to provide nucleophilic alkyl radicals that combine with the $\mathrm{C} 3$ position of the quinoxalin-2(1H)-ones.

\section{Results and discussion}

The GO material used in this investigation was prepared by Hummers oxidation of graphite and subsequent exfoliation, as reported..$^{13}$ The obtained GO material has been characterized by X-ray photoelectron spectroscopy (XPS), scanning electron microscopy (SEM), and infrared spectrum (IR) analysis (see the ESI†).

Based on our hypothesis, our investigation commenced with the reaction of $N$-methylquinoxalin-2(1H)-one (1a), phenylacetylene (2a) and the $\mathrm{CF}_{3}$-transfer regent (Langlois' reagent) in the presence of $\mathrm{GO}(80 \mathrm{wt} \%)$ and a mixture of acetonitrile and EA $(1: 1 \mathrm{v} / \mathrm{v})$ at $120^{\circ} \mathrm{C}$. It was observed that the desired product, 
<smiles>O=C(Cn1c(=O)c(-c2ccccc2)nc2ccccc21)Nc1ccc(Cl)cc1</smiles>

Antitumor and Antimicrobial<smiles>Nc1ccc([N+](=O)[O-])cc1-c1nc2ccccc2n(Cc2ccccc2)c1=O</smiles>

CFTR Activator<smiles>O=c1[nH]c2cc(C(F)(F)F)ccc2nc1CBr</smiles>

Anticancer activity in vitro against cell lines

Fig. 1 Representative biologically active quinoxalin-2(1H)-ones.

trifluoroalkylated quinoxalinone (3a) was obtained as an $E / Z$ isomeric mixture $(2.8: 1)$ with an isolated yield of $85 \%$ (Table 1 , entry 1; additional details in Tables S1 and S2 in ESI $\dagger$ ). The GO loading-screening results showed that reducing the amount of GO from $80 \mathrm{wt} \%$ to $50 \mathrm{wt} \%$ dramatically decreased the yield from $85 \%$ to $22 \%$, but increasing it further to $100 \mathrm{wt} \%$ did not show any negative effect on the yield, suggesting that GO was required only in an $80 \mathrm{wt} \%$ loading (entries 2 and 3). Screening of other temperatures including $60{ }^{\circ} \mathrm{C}$ (yield $10 \%$ ) and $140{ }^{\circ} \mathrm{C}$ (yield $79 \%$ ) did not afford any advantage over $120^{\circ} \mathrm{C}$ (entries 4 and 5). The use of a single solvent, such as MeCN or EA, led to a very low yield (entries 6 and 7). While changing to other solvents mixed in MeCN, the trifluoromethylation proceeded adversely and the yields diminished (entries 8 and 9). When Ar was used instead of air, the reaction was significantly inhibited (entry 10). The absence of GO failed to afford 3a (entry 11), indicating that this carbocatalyst was essential in the promotion of trifluoromethylation. Ultimately, we found that 1a, 2a and $\mathrm{CF}_{3} \mathrm{SO}_{2} \mathrm{Na}$ in the presence of $80 \mathrm{wt} \% \mathrm{GO}$ at $120{ }^{\circ} \mathrm{C}$ for 6 hours afforded the desired product 3 a with $85 \%$ yield $(E / Z=$ $2.8: 1$, which was determined by the proton NMR of the mixture of $E / Z$ isomers).

Subsequently, the scope of the $\mathrm{Csp}-\mathrm{CF}_{3}$ bond addition/ trifluoromethylation reaction was studied. The influence of substituents on the quinoxalin-2 $(1 H)$-one moiety is illustrated in Table 2. For the $N$-methylquinoxalinones with substituents at the 5 or 6 position of the benzene ring, the corresponding trifluoromethylated quinoxalin-2(1H)-ones $3 \mathbf{a}-3 \mathbf{h}$ were obtained with moderate to good yields (43-85\%). Various $N$-substituted quinoxalin-2(1H)-ones could react smoothly. Overall, the transformation of para-substituted benzylquinoxalinones bearing methyl, $t$-Bu, halogen, ester, $\mathrm{CF}_{3}$ and $\mathrm{OCF}_{3}$ groups delivered the trifluoromethylated products ( $3 \mathbf{i}-3 \mathbf{3 o})$ with $65-86 \%$ yield. Moreover, $N$-alkylquinoxalinones were also compatible with the reaction and provided the corresponding products (3p$3 r$ ). Different types of $N$-substitutes, including alkenyl (3s), alkynyl (3t), ester (3u), acetylbenzene (3v) and naphthyl (3w), revealed obvious activities, and the trifluoromethylated products were isolated with satisfactory yields. It is notable that 1(prop-2-yn-1-yl) quinoxalin-2 $(1 H)$-one could also be used in the reaction, and the corresponding product (3t) was provided with $65 \%$ yield. In the case of the substrate quinoxalin-2 $(1 H)$-one, it underwent trifluoromethylative addition smoothly, leading to product $3 \mathbf{x}$ with $81 \%$ yield. Furthermore, the structure of $3 \mathbf{p}$ was unambiguously confirmed by X-ray crystallography (CCDC 2088404, see the ESI $\dagger$ ).

After exploring the scope of the quinoxalin-2(1H)-one derivatives, we turned our attention to the variation of the system of different alkynes under the optimized conditions (Table 3). Phenylacetylene substrates bearing methyl, methoxy and fluoro groups successfully carried out the $\mathrm{Csp}-\mathrm{CF}_{3}$ bond addition and afforded the desired products (3y-3aa). When aliphatic alkynes with cyclohexane or cyclopropane substituents were assessed using the present method, moderate to excellent yields were obtained (3ab-3ac). The reaction of other alkyl alkynes could work equally well to produce the desired products with good yields (3ad and 3ae). Regarding alkyl alkynes, such as those with cyano, chloro, hydroxyl, and protected hydroxyl groups, lower reaction efficiencies were generally observed, supplying the trifluoromethylquinoxalin-2(1H)-ones with yields ranging from $32 \%$ to $63 \%$ (3af to 3ai). Besides terminal alkynes, to our delight, this strategy also obeyed the trifluoromethylation of propargylic $\mathrm{Csp}-\mathrm{CF}_{3}$ bond addition to provide 3aj, ak with $53 \%$ and $51 \%$ yields, respectively.

In order to demonstrate the effectiveness of this new strategy, a gram scale reaction was performed under the standard conditions. $N$-Methylquinoxalin-2 $(1 H)$-one $(1 \mathbf{1 a})(10 \mathrm{mmol})$, phenylacetylene (2a) $(20 \mathrm{mmol})$ and Langlois' reagent $(4 \mathrm{mmol})$ were subjected to the reaction in the presence of GO $(1.28 \mathrm{~g}$, $80 \mathrm{wt} \%)$ in a mixture of acetonitrile and EA $(1: 1 \mathrm{v} / \mathrm{v})(60 \mathrm{~mL})$ at $120^{\circ} \mathrm{C}$. After $6 \mathrm{~h}$, the desired product $3 \mathrm{a}$ was obtained with $72 \%$ yield, which demonstrated the practical application of this protocol to prepare 3-trifluoroalkylated quinoxalin-2(1H)-ones on a gram-scale (Scheme 2).

To gain more insight into these multi-component tandem reactions of nucleophilic addition, we evaluated the effect of the radical scavengers butylated hydroxytoluene (BHT) and 2,2,6,6tetramethyl-1-piperidinyloxy (TEMPO). As shown in Scheme 3, the reactions were significantly inhibited, indicating that radicals might be involved. In accordance with the literature, we conceived the generation of the trifluoromethyl radical intermediate from Langlois' reagent. ${ }^{5 b, c, 14}$ TEMPO was introduced to the optimized reaction conditions and we observed the formation of TEMPO adducts ( $\mathbf{I}$ and $\mathbf{I I}$ ), which were confirmed by MS analysis (Scheme $3 \mathrm{~b}$ ). 
(a) Different methods for trifluoromethylation of organic molecules

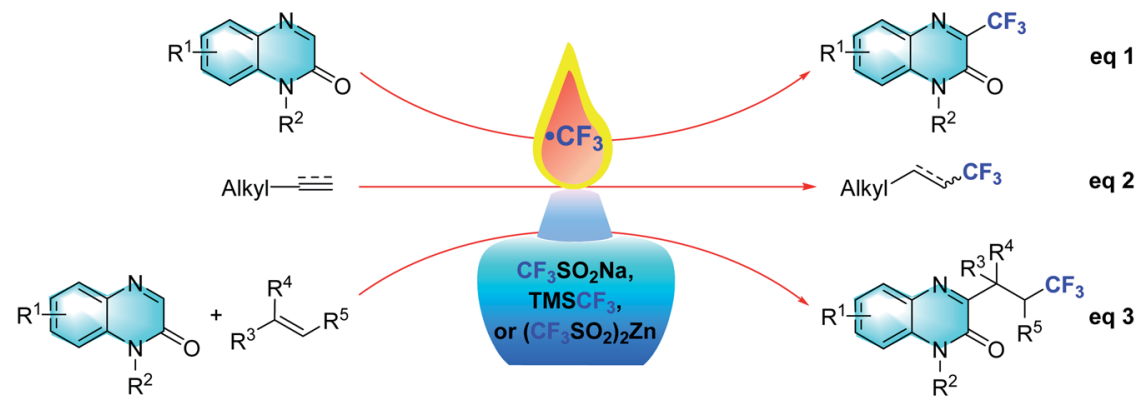

(b) This work: The $\mathrm{C}-\mathrm{H}$ alkylation of quinoxalinones at the $\mathrm{C}-3$ position with $\mathrm{CF}_{3} \mathrm{SO}_{2} \mathrm{Na}$ and alkynes

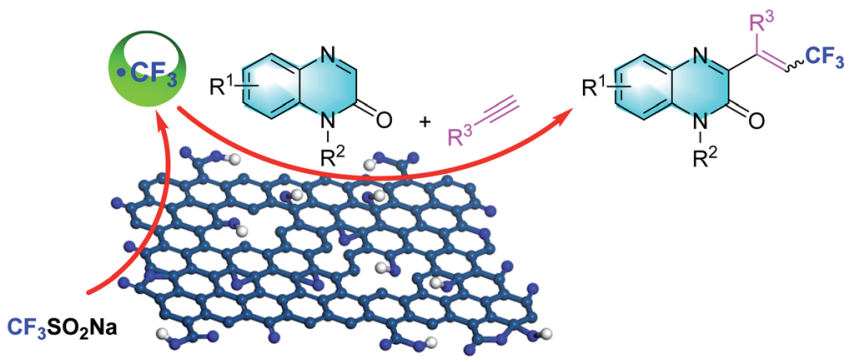

Scheme 1 Various trifluoromethylation strategies of organic molecules.

GO with high-oxygen content is usually labile at higher temperatures. X-ray photoelectron spectroscopy (XPS) and Fourier transform infrared (FT-IR) analysis showed that a large number of epoxide groups and carbonyl functional groups are lost when GO participates in the reaction (Fig. S2-S4†). GO and recovered-GO (GO-R) were analyzed by XPS in order to study

Table 1 Optimization of the reaction conditions ${ }^{a}$

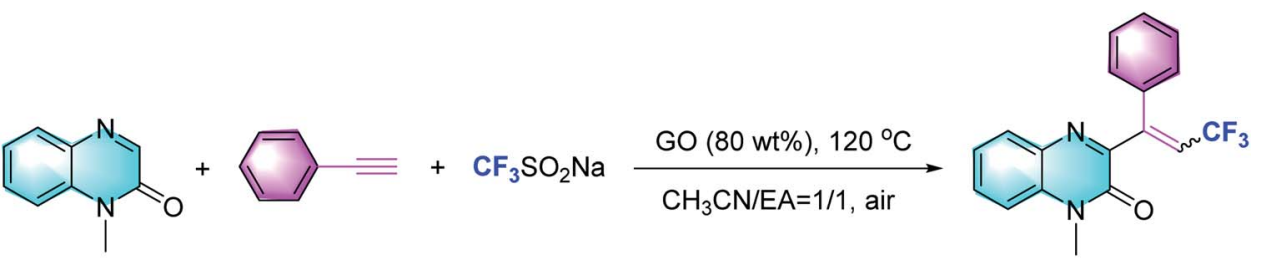

$1 a$

2a

$3 a$

\begin{tabular}{llr}
\hline Entry & Variation of the conditions & Yield $^{b}(\%)$ \\
\hline 1 & $80 \mathrm{wt} \% \mathrm{GO}, 120{ }^{\circ} \mathrm{C}, \mathrm{MeCN} / \mathrm{EA}=1: 1$ & $85(E / Z=2.8: 1)$ \\
2 & $50 \mathrm{wt} \% \mathrm{GO}$ & $22(E / Z=2.8: 1)$ \\
3 & $100 \mathrm{wt} \% \mathrm{GO}$ & $85(E / Z=2.8: 1)$ \\
4 & $60{ }^{\circ} \mathrm{C}$ & $10(E / Z=3.5: 1)$ \\
5 & $140{ }^{\circ} \mathrm{C}$ & $79(E / Z=2.6: 1)$ \\
6 & MeCN & $58(E / Z=2.7: 1)$ \\
7 & EA & $56(E / Z=2.8: 1)$ \\
8 & MeCN/THF $=1 / 1$ & $75(E / Z=2.8: 1)$ \\
9 & MeCN/1,4-dioxane $=1 / 1$ & $68(E / Z=2.6: 1)$ \\
10 & Ar & $20(E / Z=2.7: 1)$ \\
11 & Without GO & 0
\end{tabular}

${ }^{a}$ Reaction conditions: $1 \mathrm{a}\left(0.2 \mathrm{mmol}, 1\right.$ equiv.), $2 \mathrm{a}\left(0.4 \mathrm{mmol}, 2\right.$ equiv.), Langlois' reagent $(0.4 \mathrm{mmol}, 2$ equiv.), GO ( $80 \mathrm{wt} \%)$, air, $120{ }^{\circ} \mathrm{C}$, and $6 \mathrm{~h}$.

${ }^{b}$ Isolated yield. EA = ethyl acetate. 
Table 2 Conversion of the prepared quinoxalin-2(1H)-ones, phenylacetylene and Langlois' reagent into 3-trifluoromethylquinoxalin-2(1H)ones $^{a, b}$

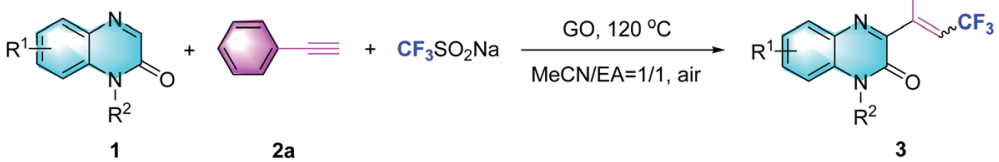

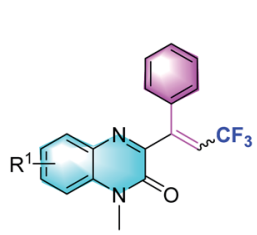

3a: $R^{1}=H, 85 \%(E / Z=2.8: 1)$

3b: $R^{1}=6,7-M e, 70 \%(E / Z=3.2: 1)$

3c: $\mathrm{R}^{1}=6-\mathrm{Ph}, 63 \%(\mathrm{E} / \mathrm{Z}=2: 1)$

3d: $R^{1}=5-O M e, 70 \%(E / Z=1.6: 1)$

3e: $R^{1}=6,7-F, 67 \%(E / Z=9.8: 1)$

3f: $R^{1}=6-C l, 72 \%(E / Z=1: 1)$

3g: $R^{1}=6-\mathrm{COOMe}, 43 \%(E / Z=8.8: 1)$

3h: $R^{1}=6-C_{3}, 55 \%(E / Z=10: 1)$

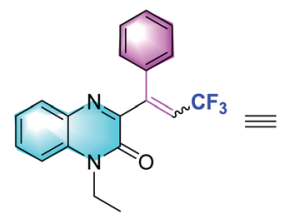

$3 p, 83 \%(E / Z=3.2: 1)$

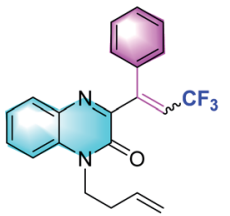

3s, $77 \%(E / Z=2.3: 1)$

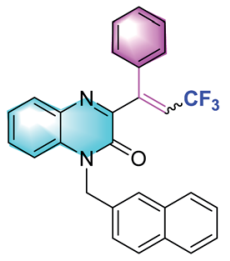

$3 w, 52 \%(E / Z=5.7: 1)$
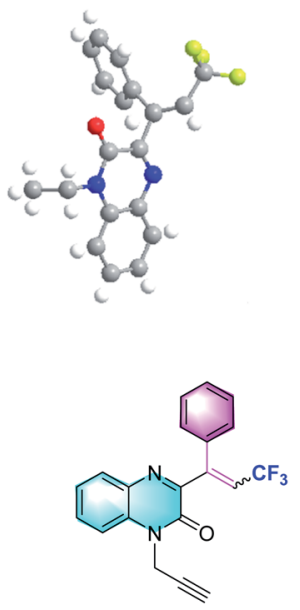

3t, $65 \%(E / Z=11: 1)$

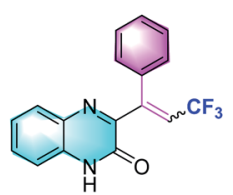

$3 \mathbf{x}, 81 \%(E / Z=3.5: 1)$

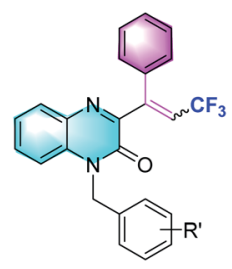

3i: $R^{\prime}=H, 86 \%(E / Z=21: 1)$

3j: $R^{\prime}=4-M e, 78 \%(E / Z=8.9: 1)$

$3 k: R^{\prime}=4{ }^{t} B u, 81 \%(E / Z=3: 1)$

3l: $R^{\prime}=4-B r, 75 \%(E / Z=8: 1)$

$3 \mathrm{~m}: \mathrm{R}^{\prime}=4-\mathrm{COOMe}, 70 \%(\mathrm{E} / \mathrm{Z}=4.5: 1)$

3n: $R^{\prime}=4-\mathrm{CF}_{3}, 79 \%(E / Z=4: 1)$

3o: $R^{\prime}=4-\mathrm{OCF}_{3}, 65 \%(E / Z=7.4: 1)$

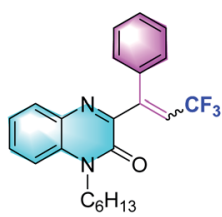

$3 q, 78 \%(E / Z=3.2: 1)$

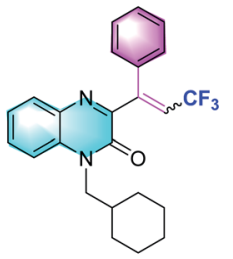

$3 r, 67 \%(E / Z=6: 1)$

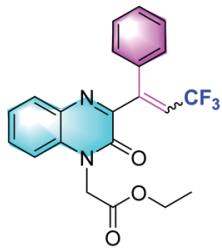

3u, $75 \%(E / Z=2.4: 1)$

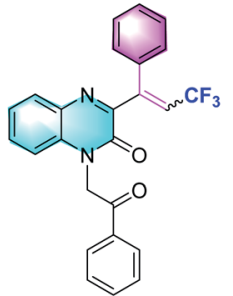

$3 v, 51 \%(E / Z=8.2: 1)$

${ }^{a}$ Reaction conditions: 1 ( $0.2 \mathrm{mmol}, 1$ equiv.), 2a (0.4 mmol, 2 equiv.), Langlois' reagent $\left(0.4 \mathrm{mmol}, 2\right.$ equiv.), GO (80 wt\%), air, $120{ }^{\circ} \mathrm{C}$, and $6 \mathrm{~h}$.
${ }^{b}$ Isolated yield.

their surface chemical state and chemical composition. The full-scale XPS spectrum (Fig. S3 $\dagger$ ) proved that GO has $\mathrm{C}$, O and $\mathrm{S}$ elements. For GO-R, the presence of $\mathrm{C}, \mathrm{O}, \mathrm{F}$ and $\mathrm{S}$ were confirmed by the survey XPS spectra, indicating that $\mathrm{NaSO}_{2} \mathrm{CF}_{3}$ was successfully doped in the carbon catalyst.

On the basis of these observations, and the established catalytic activity of graphene oxide, ${ }^{2,15,16}$ a plausible pathway for $\mathrm{Csp}-\mathrm{CF}_{3}$ bond addition has been outlined in Scheme 4. The edge sites with unpaired electrons and oxygen functional groups of the porous GO shell constitute the active sites, which enhance the formation of the trifluoromethyl radical and the superoxide radical by a tandem single-electron transfer (SET). The initial reaction of $\mathrm{NaSO}_{2} \mathrm{CF}_{3}$ generates the trifluoromethyl radical (detected by $\mathrm{MS}$ ) in the GO catalytic system by a SET process, ${ }^{17}$ and is subsequently added to the alkyne to afford the trans-alkenyl complex A (detected by MS). The $\mathrm{N}$-methylquinoxalin-2(1H)-one (1a) is immediately trapped into the generated alkenyl radical, resulting in the intermediate $\mathrm{N}$ alkylquinoxalinone radical $\mathbf{B}$. The unpaired electrons of GO reduce $\mathrm{O}_{2}$ to form $\mathrm{O}_{2}{ }^{-},{ }^{2 g, 15 b}$ which can abstract hydrogen atoms 
Table 3 Substrate scope of the Csp- $\mathrm{CF}_{3}$ bond addition/trifluoromethylation ${ }^{a, b}$

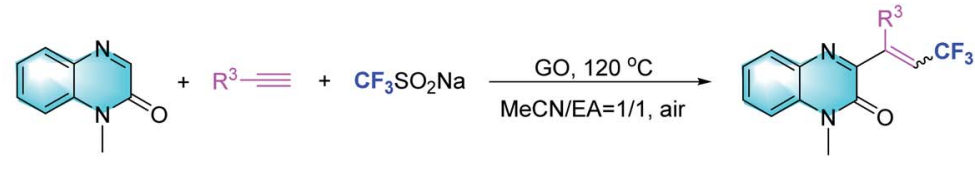

1a

2

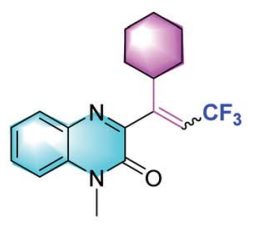

$3 a b, 57 \%(E / Z=2.8: 1)$

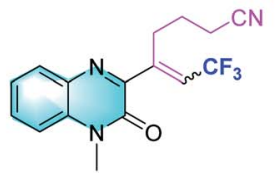

3af, $56 \%(E / Z=11: 1)$

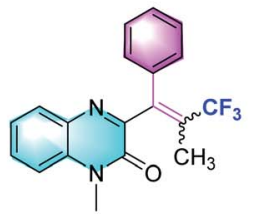

3aj, $53 \%(E / Z=2.1: 1)$

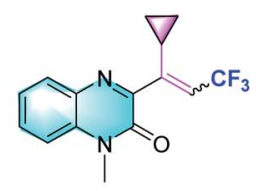

3ac, $81 \%(E / Z=6: 1)$

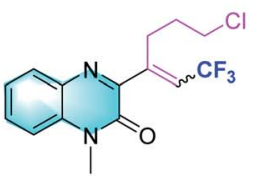

3ag, $63 \%(E / Z=12: 1)$

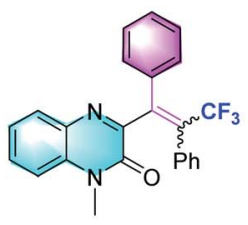

3ak, $51 \%(E / Z=1.5: 1)$ 3ah, 32\% (E/Z = 8:1) 3ai, $68 \%(E / Z=2: 1)$

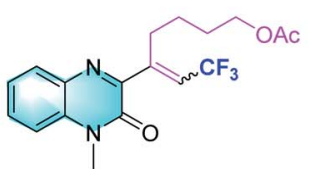

${ }_{b}^{a}$ Reaction conditions: $1 \mathrm{a}\left(0.2 \mathrm{mmol}, 1\right.$ equiv.), $2 \mathrm{a}\left(0.4 \mathrm{mmol}, 2\right.$ equiv.), Langlois' reagent ( $0.4 \mathrm{mmol}, 2$ equiv.), GO (80 wt\%), air, $120{ }^{\circ} \mathrm{C}$, and $6 \mathrm{~h}$. ${ }^{b}$ Isolated yield.

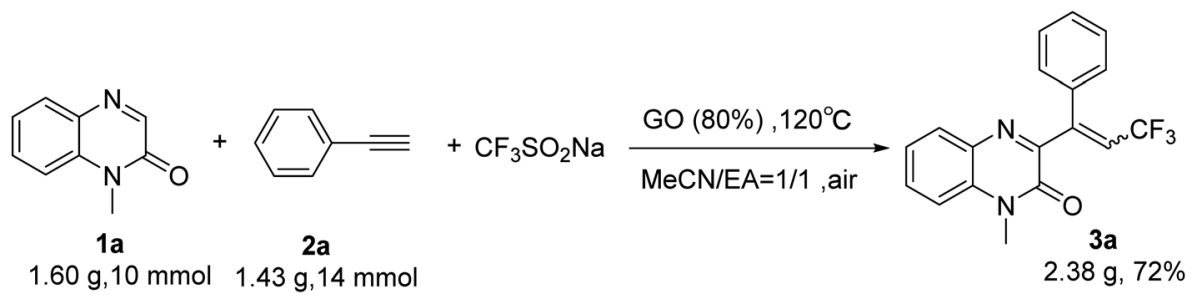

Scheme 2 Gram-scale preparation of $3 a$. (a)<smiles>Cn1c(=O)cnc2ccccc21</smiles>

$1 \mathbf{a}$

(b)<smiles>Cn1c(=O)cnc2ccccc21</smiles>

$1 \mathrm{a}$

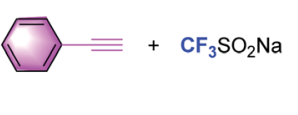

$2 a$ $\underset{\text { BHT (2 equiv) }}{\stackrel{\text { standard conditions }}{\longrightarrow}}$<smiles>C/C(=C\C(F)(F)F)c1nc2ccccc2n(C)c1=O</smiles>

$3 a, 0 \%$
Scheme 3 Mechanistic studies.

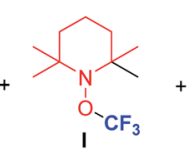

$[\mathrm{M}+\mathrm{H}]^{+}: 226.1416$ calculated: 226.1413

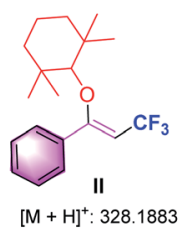

calculated: 328.1883 


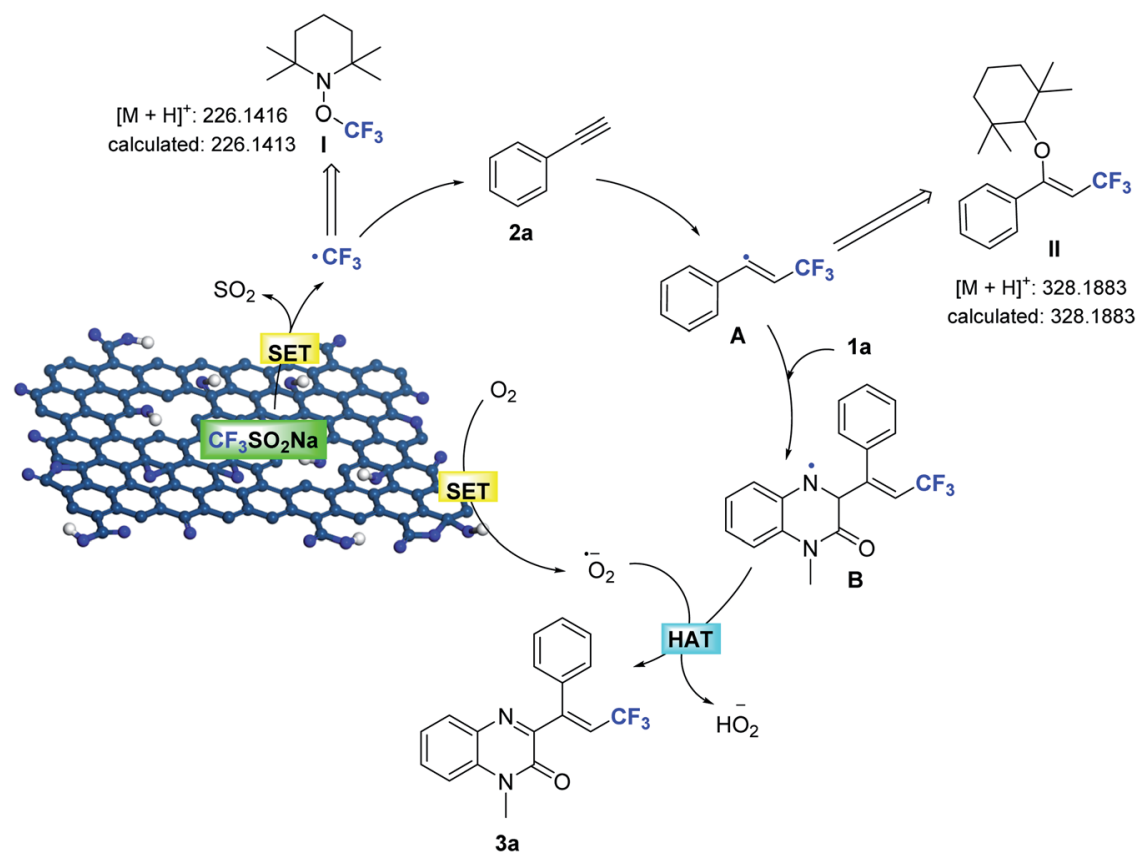

Scheme 4 Proposed catalytic cycle for the trifluoromethylation of alkynes.

from radical $\mathbf{B}$ to furnish the adduct product $\mathbf{3 a}$. At the same time, the active sites of porous GO are released to maintain the catalytic cycle.

\section{Conclusions}

We have developed a tandem radical addition strategy of an $\mathrm{O}_{2}$ assisted one-pot process to synthesize 3-trifluoroalkylated quinoxalin-2(1H)-ones under ambient atmosphere and $80 \mathrm{wt} \%$ GO content. Mechanistic studies reveal that GO affected the formation of trifluoromethyl and superoxide radicals and was subsequently capable of performing an auto-tandem radical addition. This unique multi-component tandem reaction facilitated access to $\mathrm{CF}_{3}$-substituted quinoxalinones by the catalysis of a readily available carbon material in the absence of metal catalysts. In a broader perspective, these transformations also emphasize the potential of GO in synthetic chemistry, particularly in metal-free synthesis, rather than simply using a precursor to graphene-based materials.

\section{Conflicts of interest}

There are no conflicts to declare.

\section{Acknowledgements}

The authors are grateful to the National Natural Science Foundation of China (21462002), the Jiangxi Province Office of Education Support Program (GJJ190757, GJJ190788), the Graduate Innovation Project of Gannan Medical University (YC2021X014), the Practice and Innovation Training Program for College Students in Jiangxi Province (201910413013) and the
Scientific Research Project of Gannan Medical University (ZD201819) for their financial support.

\section{References}

1 (a) H. Wu, C. Su, R. Tandiana, C. Liu, C. Qiu, Y. Bao, J. Wu, Y. Xu, J. Lu, D. Fan and K. P. Loh, Angew. Chem., Int. Ed., 2018, 57, 10848; (b) C. Tan, X. Cao, X.-J. Wu, Q. He, J. Yang, X. Zhang, J. Chen, W. Zhao, S. Han, G.-H. Nam, M. Sindoro and H. Zhang, Chem. Rev., 2017, 117, 6225; (c) C. K. Chua and M. Pumera, Chem.-Eur. J., 2015, 21, 12550; (d) D. R. Dreyer, A. D. Todd and C. W. Bielawski, Chem. Soc. Rev., 2014, 43, 5288; (e) S. Navalon, A. Dhakshinamoorthy, M. Alvaro and H. Garcia, Chem. Rev., 2014, 114, 6179; (f) C. Su and K. P. Loh, Acc. Chem. Res., 2013, 46, 2275.

2 (a) J. Soni, A. Sethiya, N. Sahiba and S. Agarwal, Appl. Organomet. Chem., 2021, e6162; (b) L. Lombardi and M. Bandini, Angew. Chem., Int. Ed., 2020, 59, 20767; (c) A. Bahuguna, A. Kumar and V. Krishnan, Asian J. Org. Chem., 2019, 8, 1263; (d) J. Zhang, S. Chen, F. Chen, W. Xu and H. Gong, Adv. Synth. Catal., 2017, 359, 2358; (e) P. Tang, G. Hu, M. Li and D. Ma, ACS Catal., 2016, 6, 6948; (f) F. M. Koehler and W. J. Stark, Acc. Chem. Res., 2013, 46, 2297; (g) C. Su, M. Acik, K. Takai, J. Lu, S. Hao, Y. Zheng, P. Wu, Q. Bao, T. Enoki, Y. J. Chabal and K. P. Loh, Nat. Commun., 2012, 1298; (h) A. Dhakshinamoorthy, M. Alvaro, P. Concepción, V. Fornés and H. Garcia, Chem. Commun., 2012, 48, 5443; (i) D. S. Su, J. Zhang, B. Frank, A. Thomas, X. Wang, J. Paraknowitsch and R. Schlögl, ChemSusChem, 2010, 3, 169. 
3 (a) T.-F. Yeh, C.-Y. Teng, L.-C. Chen, S.-J. Chen and H. Teng, J. Mater. Chem. A, 2016, 4, 2014; (b) N. Zhang, M.-Q. Yang, S. Liu, Y. Sun and Y.-J. Xu, Chem. Rev., 2015, 115, 10307; (c) J. D. Roy-Mayhew and I. A. Aksay, Chem. Rev., 2014, 114, 6323; (d) C. Chung, Y.-K. Kim, D. Shin, S.-Y. Ryoo, B.-H. Hong and D.-H. Min, Acc. Chem. Res., 2013, 46, 2211.

4 (a) J.-P. Hu, C.-Q. Tian, M. S. Damaneh, Y.-L. Li, D.-Y. Cao, K.-K. Lv, T. Yu, T. Meng, D.-Q. Chen, X. Wang, L. Chen, J. Li, S.-S. Song, X.-J. Huan, L.-H. Qin, J.-K. Shen, Y.-Q. Wang, Z.-H. Miao and B. Xiong, J. Med. Chem., 2019, 62, 8642; (b) S. Hussain, S. Parveen, X. Hao, S. Zhang, W. Wang, X. Qin, Y. Yang, X. Chen, S. Zhu, C. Zhu and B. Ma, Eur. J. Med. Chem., 2014, 80, 383; (c) R. Liu, Z.-H. Huang, M. G. Murray, X.-Y. Guo and G. Liu, J. Med. Chem., 2011, 54, 5747.

5 (a) S. Schiesser, H. Chepliaka, J. Kollback, T. Quennesson, W. Czechtizky and R. J. Cox, J. Med. Chem., 2020, 63, 13076; (b) E. H. Oh, H. J. Kim and S. B. Han, Synthesis, 2018, 50, 3346; (c) H.-X. Song, Q.-Y. Han, C.-L. Zhao and C.-P. Zhang, Green Chem., 2018, 20, 1662; (d) X. Yang, T. Wu, R. J. Phipps and F. D. Toste, Chem. Rev., 2015, 115, 826; (e) W. Zhu, J. Wang, S. Wang, Z. Gu, J. L. Aceña, K. Izawa, H. Liu and V. A. Soloshonok, J. Fluorine Chem., 2014, 167, 37; $(f)$ T. Furuya, A. S. Kamlet and T. Ritter, Nature, 2011, 473, 470.

6 L. Li, X. Mu, W. Liu, Y. Wang, Z. Mi and C.-J. Li, J. Am. Chem. Soc., 2016, 138, 5809.

7 (a) C.-T. Chen, Y.-P. Chen, B.-Y. Tsai, Y.-Y. Liao, Y.-C. Su, T.-C. Chen, C.-H. Lu, R. Fujii, K. Kawashima and S. Mori, ACS Catal., 2020, 10, 3676; (b) Z.-Q. Zhang, Y.-H. Xu, J.-C. Dai, Y. Li, J. Sheng and X.-S. Wang, Org. Lett., 2021, 23, 2194.

8 C. Zhang, Org. Biomol. Chem., 2014, 12, 6580.

9 (a) C. P. Johnston, T. H. West, R. E. Dooley, M. Reid, A. B. Jones, E. J. King, A. G. Leach and G. C. Lloyd-Jones, J. Am. Chem. Soc., 2018, 140, 11112; (b) X. Liu, C. Xu, M. Wang and Q. Liu, Chem. Rev., 2015, 115, 683.

10 (a) N. B. Dutta, J. Bori, P. Gogoi and G. Baishya, ChemistrySelect, 2021, 6, 1471; (b) Z. Wei, S. Qi, Y. Xu, H. Liu, J. Wu, H. Li, C. Xia and G. Duan, Adv. Synth. Catal.,
2019, 361, 5490; (c) W. Xue, Y. Su, K.-H. Wang, L. Cao, Y. Feng, W. Zhang, D. Huang and Y. Hu, Asian J. Org. Chem., 2019, 8, 887; (d) J. Wang, B. Sun, L. Zhang, T. Xu, Y. Xie and C. Jin, Asian J. Org. Chem., 2019, 8, 1942; (e) G.-Y. Dou, Y.-Y. Jiang, K. Xu and C.-C. Zeng, Org. Chem. Front., 2019, 6, 2392; $(f)$ L. Wang, J. Zhao, Y. Sun, H.-Y. Zhang and Y. Zhang, Eur. J. Org. Chem., 2019, 6935; (g) L. Wang, Y. Zhang, F. Li, X. Hao, H.-Y. Zhang and J. Zhao, Adv. Synth. Catal., 2018, 360, 3969.

11 (a) X.-J. Shang, R. Luo, J. Zhu and Z.-Q. Liu, Tetrahedron Lett., 2021, 62, 152683; (b) H. Sun, G. Cui, H. Shang and B. Cui, J. Org. Chem., 2020, 85, 15241; (c) S. Tanaka, Y. Nakayama, Y. Konishi, T. Koike and M. Akita, Org. Lett., 2020, 22, 2801; (d) W. Long, P. Lian, J. Li and X. Wan, Org. Biomol. Chem., 2020, 18, 6483; (e) K. Matcha and A. P. Antonchick, Transition, Eur. J. Org. Chem., 2019, 309; (f) Z. Hang, Z. Li and Z.-Q. Liu, Org. Lett., 2014, 16, 3648.

12 (a) N. Meng, Y. Lv, Q. Liu, R. Liu, X. Zhao and W. Wei, Chin. Chem. Lett., 2021, 32, 258; (b) N. Meng, L. Wang, Q. Liu, Q. Li, Y. Lv, H. Yue, X. Wang and W. Wei, J. Org. Chem., 2020, 85, 6888; (c) Z. Shao, S. Zhang, Y. Chen, Y.-L. Liu, R.-Y. Tang and Z. Li, Tetrahedron, 2020, 76, 131199.

13 (a) W. S. Hummers and R. E. Offeman, J. Am. Chem. Soc., 1958, 80, 1339; (b) A. Primo, F. Neatu, M. Florea, V. Parvulescu and H. García, Nat. Commun., 2014, 5, 5291.

14 (a) E. Merino and C. Nevado, Addition of $\mathrm{CF}_{3}$ Across Unsaturated Moieties: A Powerful Functionalization Tool, Chem. Soc. Rev., 2014, 43, 6598; (b) C. Zhang, Application of Langlois' Reagent in Trifluoromethylation Reactions, Adv. Synth. Catal., 2014, 356, 2895.

15 (a) Y. Gao, P. Tang, H. Zhou, W. Zhang, H. Yang, N. Yan, G. $\mathrm{Hu}, \mathrm{D} . \mathrm{Mei}$ J. Wang and D. Ma, Angew. Chem., Int. Ed., 2016, 55, 3124; (b) G. Lv, H. Wang, Y. Yang, T. Deng, C. Chen, Y. Zhu and X. Hou, ACS Catal., 2015, 5, 5636.

16 (a) X.-J. Peng, D. Hu, P.-P. Huang, H.-W. Liao, Y. Zeng, Q. Liu and L.-X. Liu, Org. Chem. Front., 2020, 7, 1796; (b) X.-J. Peng, Y. Zeng, Q. Liu, L.-X. Liu and H.-S. Wang, Org. Chem. Front., 2019, 6, 3615.

17 J. Zhang, Y. Yang, J. Fang, G.-J. Deng and H. Gong, Chem.Asian. J., 2017, 12, 2524. 